\title{
Intramolecular 1,8- versus 1,6-Hydrogen Atom Transfer between Pyranose Units in a(1f4)-Disaccharide Model Promoted by Alkoxyl Radicals. Conformational and Stereochemical Requirements
}

\author{
Angeles Mart'in, Ine's Pe'rez-Mart'n, Luis M. Quintanal, and Emesto Suárez*
}

Instituto de Productos Naturales y Agrobiolog'ta del C.S.I.C.,

Carretera de La Esperanza 3, 38206 La Laguna, Tenerife, Spain

esuarez@ipna.csic.es

Received February 27, 2007

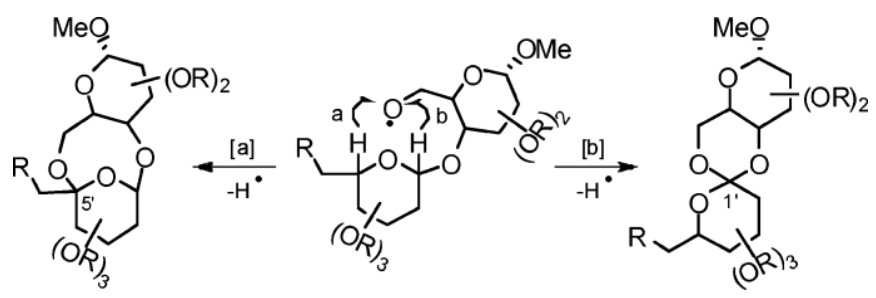

The stereochemical and conformational factors controlling the intramolecular hydrogen atom transfer (HAT) reaction between the two pyranose units in a (1f4)-disaccharide when promoted by a primary 6-O-yl radical are studied. Models with $r$-D-Glcp-(1f4)- $\beta$-D-Glcp or $r-L-R h a m p-(1 f 4)-$ $\mathrm{r}-\mathrm{D}-$ Galp skeletons lead exclusively to the abstraction of $\mathrm{H}-\mathrm{C}-5^{\prime}$ and the formation, through a nine-membered transition state, of a $1,3,5-$ trioxocane ring system in a stable boat-chair conformation. Notwithstanding, derivatives of $r-L-R h a m p-(1 f 4)-r-D-G l c p$ abstract exclusively H-C-1' through a seven-membered transition state and therefore lead to an interglycosidic spiro orthoester.

In a previous paper from this laboratory, we described a most unusual 1,8-hydrogen atom transfer (HAT) between the two glucopyranose units of a R-D-Glc $p$-(1f4)- $\$-D-G l c p$ disaccharide (D-maltose) (1) through a nine-membered transition state. ${ }^{1}$ The hydrogen abstraction from $\mathrm{C}-5^{\prime}$ is promoted, in a highly efficient and completely regioselective manner, by the 6-O-yl radical (A) generated in situ from the photolysis of the primary alcohol in the presence of (diacetoxyiodo)benzene and iodine (Scheme 1). The C-radical (B) evolves to a final 1,3,5-trioxocane cyclized derivative (2), presumably via oxidation to an oxonium ion intermediate. The process may also be accomplished under reductive conditions by reaction of the 6- $O$-phthalimide derivative with tri- $n$-butyltin

(1) Francisco, C. G.; Herrera, A. J.; Kennedy, A. R.; Melia'n, D.; Suárez, E. Angew. Chem., Int. Ed. 2002, 41, 856-858. hydride and AIBN. In this case, the $\mathrm{C}$-radical reduction gave predominant inversion of the configuration at $\mathrm{C}-5^{\prime}$. In principle, this may be a synthetically useful protocol for the remote functionalization of the $\mathrm{C}-5^{\prime}$ carbon atom or for the inversion of configuration at this center and consequent transformation of this D-glucose moiety in L-idose. None of these synthetic processes is a trivial task under more classical conditions. ${ }^{2}$

A question that immediately arises is whether and to what extent this methodology can be applied to other ( $1 \mathrm{f} 4)$ -

(2) (a) Ermolenko, L.; Sasaki, N. A. J. Org. Chem. 2006, 71, 693-703. (b) Takahashi, H.; Shida, T.; Hitomi, Y.; Iwai, Y.; Miyama, N.; Nishiyama, K.; Sawada, D.; Ikegami. S. Chem.-Eur. J. 2006, 12, 5868-5877. (c) Takeuchi, M.; Taniguchi, T.; Ogasawara, K. Chirality 2000, 41, 338-341. (d) Ko, S. Y.; Lee, A. W. M.; Masamune, S.; Reed, L. A.; Sharpless, K. B.; Walker, F. J. Tetrahedron 1990, 46, 245-264. 


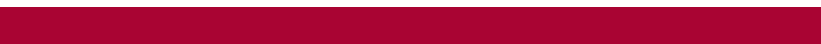

Scheme 1. HAT Reaction of D-Maltose
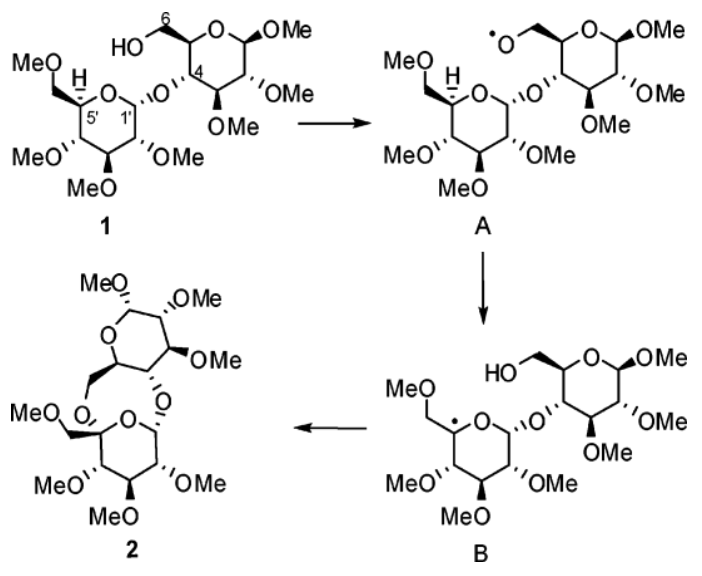

disaccharides or whether it is exclusive to D-maltose. As can be easily determined by molecular mechanics calculations, the 1,3,5-trioxocane ring in $\mathbf{2}$ adopts a constrained, stable, boat-chair conformation. ${ }^{3} \mathrm{We}$ therefore analyzed the conformation of the ring for all 16 possible disaccharide diastereoisomers of the four chiral centers involved in the cyclization step (C-5', C-1', C-4, and C-5). ${ }^{4}$ Only four structural arrangements (A-D) were found that can easily accommodate 1,3,5-trioxocane rings in stable boat-chair conformations of similar minimized energies $(\Delta E$ e $1.5 \mathrm{kcal} /$ mol), as depicted in Table 1. Among the four structures, two

Table 1. Conformations of 1,3,5-Trioxocane Rings

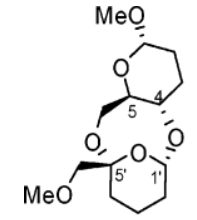

A

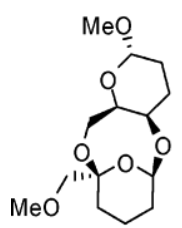

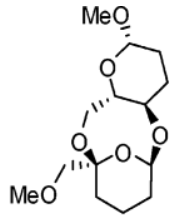

B

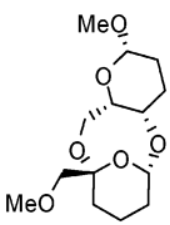

D

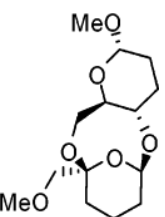

E

\begin{tabular}{ccccccl}
\hline arrangement & C-5 $^{\prime}$ & C-1 & C-4 & C-5 & conformation & $\Delta E^{a}$ \\
\hline $\mathrm{A}^{b}$ & $S$ & $S$ & $S$ & $R$ & boat-chair & 0 \\
B & $R$ & $R$ & $R$ & $S$ & boat-chair & 0.3 \\
C & $R$ & $R$ & $R$ & $R$ & boat-chair & 1.1 \\
D & $S$ & $S$ & $S$ & $S$ & boat-chair & 1.5 \\
E & $R$ & $R$ & $S$ & $R$ & boat-boat & 3.3
\end{tabular}

${ }^{a}$ In kcal/mol. ${ }^{b}$ D-Maltose arrangement.

pairs of pseudoenantiomers, $\mathrm{A}$ and $\mathrm{B}$ and $\mathrm{C}$ and $\mathrm{D}$, with very similar energies ( $\Delta \Delta E$ e $0.4 \mathrm{kcal} / \mathrm{mol})$ can be identified.

Another question that now arises is whether, in those compounds where the formation of the 1,3,5-trioxocane ring would be energetically disfavored, the HAT reaction could alternatively take place at $\mathrm{C}-1^{\prime}$ through a seven-membered transition state. This last reaction should give an interesting spiro ortho ester (such as 12, Scheme 3), which is a substructure present in several antibiotics of the orthosomycin ${ }^{5}$ and erythromycin ${ }^{6}$ families and consequently has attracted considerable attention from synthetic organic chemists. ${ }^{7}$

This may be the case of the fifth-lowest-energy structural arrangement $\mathrm{E}$ which is approximately $3 \mathrm{kcal} / \mathrm{mol}$ more energetic than the arrangement of D-maltose A and where the 1,3,5-trioxocane ring adopts a theoretically less-stable boat-boat conformation (Table 1).

To address these issues, we decided to prepare disaccharides R-L-Rhamp-(1f4)-R-D-Galp 3 and R-L-Rhamp-(1f4)R-D-Glcp 11 which, after HAT, could hypothetically lead to structural arrangements $\mathrm{C}$ and $\mathrm{E}$, respectively. The selection of $\mathbf{3}$ was also made considering that arrangement $\mathrm{C}$ belongs to a pseudoenantiomeric pair different from that of D-maltose and slightly more energetic.

Compounds $\mathbf{3}$ and $\mathbf{1 1}$ were effectively synthesized by TMSOTf-mediated glycosylation of suitably protected Dgalactopyranose and D-glucopyranose derivatives, respectively, using 2,3,4-tri- $O$-acetyl-R-L-rhamnopyranosyl trichloroacetimidate as the glycosyl donor, as described in the Supporting Information. ${ }^{8}$

The alkoxyl radicals were generated by oxidation of the primary alcohol with (diacetoxyiodo)benzene in the presence

(3) To the best of our knowledge, studies on the conformation of the 1,3,5-trioxocane ring are scarce: (a) McCullough, K. J.; Masuyama, A.; Morgan, K. M.; Nojima, M.; Okada, Y.; Satake, S.; Takeda, S.-y. J. Chem. Soc., Perkin Trans. 1 1998, 2353-2362. For the conformation of a related 1,3,6-trioxocane derivative, see: (b) Buchanan, G. W.; Driega, A. B.; Laister, R. C.; Bourque, K. Magn. Reson. Chem. 1999, 37, 401-406. See also: (c) Anet, F. A. L. In Conformational Analysis of Medium-Sized Heterocycles; Glass, R. S., Ed.; VCH: New York, 1988; pp 35-95. (d) McGuire, R. R.; Pflug, J. L.; Rakowsky, M. H.; Shackelford, S. A.; Shaffer, A. A. Heterocycles 1994, 38, 1979-2004. (e) Burkert, U. Z. Naturforsch 1980, $35 b, 1479-1481$.

(4)Molecular mechanics calculations were carried out by using CS Chem3D, version 10.0. For the purpose of simplification, substituents at C2, C-3, C-2', C-3', and C-4' in the carbohydrate skeleton were not considered in the calculation.

(5) (a) Ganguly, A. K. Oligosaccharide Antibiotics. In Topics inAntibiotic Chemistry; Sammes, P. G., Ed.; Ellis Horwood: Chichester, 1978; Vol. 2, Part B, p 49. (b) Wright, D. E. Tetrahedron 1979, 35, 1207-1237. (c) Ollis, W. D.; Smith, C.; Wright, D. E. Tetrahedron 1979, 35, 105-127.

(6)(a) Martin, J. R.; Egan, R. S.; Goldstein, A. W.; Collum, P. Tetrahedron 1975, 31, 1985-1989. (b) Mikami, Y.; Yazawa, K.; Nemoto, A.; Komaki, H.; Tanaka, Y.; Grafe, U. J. Antibiot. 1999, 52, 201-202.

(7) (a) Ohtake, H.; Ichiba, N.; Ikegami, S. J. Org. Chem. 2000, 65, 8164 8170. (b) Ohtake, H.; Ichiba, N.; Ikegami, S. J. Org. Chem. 2000, 65, 8171 8179. (c) Ohtake, H.; Ikegami, S. Org. Lett. 2000, 2, 457-460. (d) Nicolaou, K. C.; Mitchell, H. J.; Fylaktakidou, K. C.; Suzuki, H.; Rodr'iguez, R. M. Angew. Chem., Int. Ed. 2000, 39, 1089-1093. (e) Nicolaou, K. C.; Fylaktakidou, K. C.; Mitchell, H. J.; van Delft, F. L.; Rodr'iguez, R. M.; Conley, S. R.; Jin, Z. Chem.-Eur. J. 2000, 6, 3166-3185. (f) Trumtel, M.; Tavecchia, P.; Veyrieres, A.; Sinaÿ, P. Carbohydr. Res. 1990, 202, 257275. (g) Tamura, J.; Horito, S.; Hashimoto, H.; Yoshimura, J. Carbohydr. Res. 1988, 174, 181-199. (h) Beau, J.-M.; Jaurand, G.; Esnault, J.; Sinay”, P. Tetrahedron Lett. 1987, 28, 1105-1108. (i) Yoshimura, J.; Horito, S.; Tamura, J.; Hashimoto, H. Chem. Lett. 1985, 1335-1338. (j) Asano, K.; Horito, S.; Saito, A.; Yoshimura, J. Carbohydr. Res. 1985, 136, 1-11. (k) Asano, K.; Horito, S.; Yoshimura, J.; Nakazawa, T.; Ohya, Z.- I.; Watanabe, T. Carbohydr. Res. 1985, 138, 325-328.

(8) (a) Schmidt, R. R.; Jung, K.-H. In PreparatiVe Carbohydrate Chemistry; Hanessian, S., Ed.; Marcel Dekker: New York, 1997; pp 283 312. For the use of 2,3,4-tri- $O$-acetyl-R-L-rhamnopyranosyl trichloroacetimidate as a glycosyl donor, see: (b) Wang, J.; Li, J.; Tuttle, D.; Takemoto, J. Y.; Chang, C.-W. T. Org. Lett. 2002, 4, 3997-4000. (c) Gurjar, M. K.; Mainkar, A. S. Tetrahedron 1992, 48, 6729-6738. 
of iodine, under either thermal or visible light irradiation conditions. To acquire additional insight into the HAT reaction mechanism, the alkoxyl radicals were also prepared under reductive conditions by treatment of the 6-Ophthalimido derivatives 6 and 13 with $n-\mathrm{Bu}_{3} \mathrm{SnH} / \mathrm{AIBN}$ and $n-\mathrm{Bu}_{3} \mathrm{SnD} / \mathrm{AIBN}$ in benzene solutions. ${ }^{9}$ The synthesis of $6-O-$ phthalimido derivatives was readily achieved from the corresponding alcohol and $N$-hydroxyphthalimide under Mitsunobu conditions. ${ }^{10}$

The results of the HAT reaction for the disaccharide R-LRhamp-(1f4)-R-D-Galp 3 are outlined in Scheme 2. Under

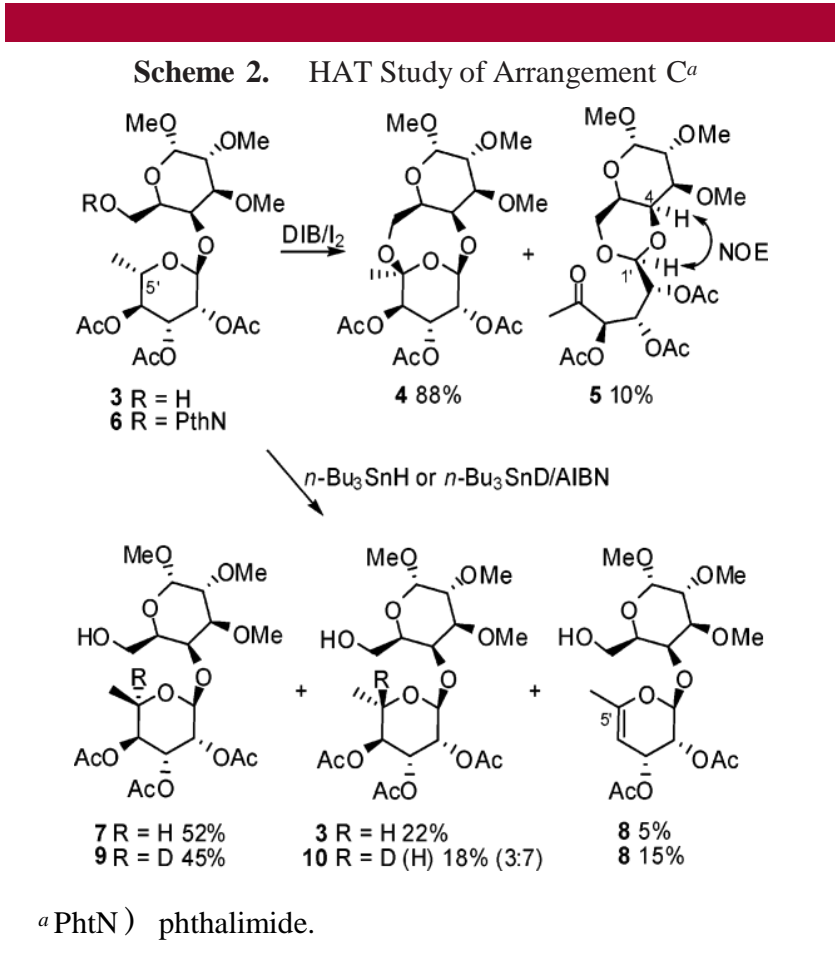

oxidative conditions, the alcohol 3 was transformed into the trioxocane 4 in good yield. A small amount (10\%) of methyl ketone $\mathbf{5}$ was also formed, in which the NOE interaction observed between $\mathrm{H}-1^{\prime}$ and $\mathrm{H}-4$ corroborates the assignment of the $(S)$-configuration at $\mathrm{C}-1^{\prime}$. Because the ketone 5 was presumably formed by partial acid-catalyzed rearrangement of 4 under the reaction conditions, the HAT reaction proceeded with absolute regioselectivity by abstraction of the hydrogen at C-5' in almost quantitative yield.

The phthalimide 6 by reaction with $n$-Bu $3 \mathrm{SnH} / \mathrm{AIBN}$ was transformed into three compounds: disaccharide 7 formed by hydrogen abstraction at $\mathrm{C}-5^{\prime}$ and radical quenching by the stannane with inversion of configuration; the precursor alcohol $\mathbf{3}$ which, evidently, arises by abstraction and retention

(9) (a) Crich, D.; Huang, X.; Newcomb, M. J. Org. Chem. 2000, 65, 523-529. (b) Crich, D.; Huang, X.; Newcomb, M. Org. Lett. 1999, 1,225 227. (c) Kim, S.; Lee, T. A.; Song, Y. Synlett 1998, 471-472. (d) Okada, K.; Okamoto, K.; Oda, M. J. Chem. Soc., Chem. Commun. 1989, 16361637. (e) Barton, D. H. R.; Blundell, P.; Jaszberenyi, J. Cs. Tetrahedron Lett. 1989, 30, 2341-2344. (f) Okada, K.; Okamoto, K.; Oda, M. J. Am. Chem. Soc. 1988, 110, 8736-8738.

(10) (a) Mitsunobu, O. Synthesis 1981, 1-28. (b) Grochowski, E.; Jurczak, J. Synthesis 1976, 682-684. of configuration at $\mathrm{C}-5^{\prime}$, simply by reduction of the O-radical prior to the abstraction reaction, or by a combination of these two mechanisms; and finally the olefin $\mathbf{8}$ formed by reductive elimination of the acetate group at $\mathrm{C}-4^{\prime}$.

The structure of 7, where the original R-L-rhamnopyranosyl moiety has been transformed into a 6-deoxy-\$-Dgulopyranosyl derivative and, consequently, the pyranose ring has been changed from a ${ }^{1} C_{4}$ to a ${ }^{4} C_{1}$ conformation, was easily established by analyzing the coupling constants of the ring hydrogens by ${ }^{1} \mathrm{H}$ NMR spectroscopy. ${ }^{11}$

To confirm the structures and to shed light on the HAT mechanism, the reduction of the phthalimide 6 was also made with $n-\mathrm{Bu}_{3} \mathrm{SnD}$ (Scheme 2). Analysis of the isotopic distribution in compound $\mathbf{9}$ showed a complete substitution of deuterium at C-5'.12 On the other hand, only $30 \%$ of deuterium labeling was found in compound $\mathbf{1 0}$, and therefore the reduction of the O-radical is responsible for the unlabeled molecules. It can thus be concluded that the abstraction at C-5' occurs with an inversion-retention ratio of approximately 9:1. The formation of unlabeled olefin 8 supports the mechanism of free-radical reductive $\$$-elimination proposed.

The results pertaining to the reactivity of alkoxyl radicals generated from alcohol $\mathbf{1 1}$ and phthalimide $\mathbf{1 3}$ are depicted in Scheme 3. The reaction of disaccharide R-L-Rhamp-

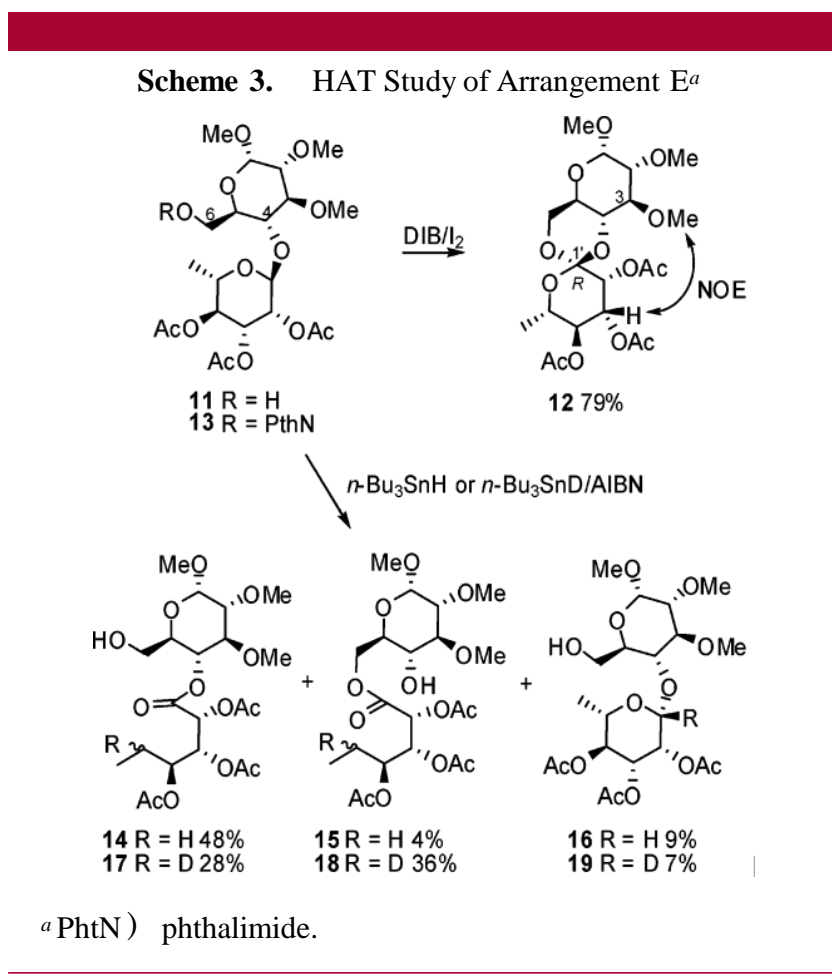

(1f4)-R-D-Glcp 11 under oxidative conditions gave rise to the spiro ortho ester $\mathbf{1 2}$ in good yield. Complete regio- and

(11)Assignments were made by DEPT and 2D COSY, HMBC, and HSQC experiments.

(12) The deuterium position was determined by the coupling with the geminal carbon atom and also by the small yet significant displacement of the adjacent carbon signals in the ${ }^{13} \mathrm{C}$ NMR spectra. See: Berger, S. In Encyclopedia of Nuclear Magnetic Resonance; Grant, D. M., Harris, R. K., Eds.; John Wiley: Chichester, 1996; Vol. 2, pp 1168-1172. 
stereoselectivity was observed; the abstraction occurred exclusively at $\mathrm{C}-1^{\prime}$, and no compounds resulting from abstraction at $\mathrm{C}-5^{\prime}$ could be detected in the crude reaction mixture. The stereochemistry at the spiro center was tentatively assigned as $R$ on the basis of the NOE interaction observed between $\mathrm{H}^{-} \mathrm{C}-3^{\prime}$ and the methoxy group at $\mathrm{C}-3 .{ }^{13}$

The situation changed, however, when the HAT reaction was performed under reductive conditions. The expected

compound 16, formed by abstraction at $\mathrm{C}-1^{\prime}$ and radical reduction by the stannane with inversion of configuration, was obtained in only $9 \%$ yield. ${ }^{14}$ The main reaction product was the ester 14, originated also by abstraction at $\mathrm{C}-1^{\prime}$ but where the radical was stabilized by $\$$-fragmentation of the

$\mathrm{C}-5^{\prime}-\mathrm{O}$ bond prior to the stannane quenching. A small amount of transesterified ester $\mathbf{1 5}$ was also obtained, where the ester group had evidently migrated from the 4- to the 6-position. ${ }^{15}$

NMR spectral analysis of deuterated compounds 17 and 18 confirmed the structures and the mechanism proposed. ${ }^{12}$ The complete deuteration of $\mathbf{1 9}$ and the isolation of a small amount of the undeuterated alcohol precursor 11 implicate

(13) The three methoxy groups can be easily distinguished by 2D HSQC and $\mathrm{HMBC}$ correlations. Furthermore, the observed coupling constants for the hydrogens at C-4 and C-6 $\left.\left(J_{4,5}\right) \quad 9.5 \mathrm{~Hz}, J_{5,6 \mathrm{e}}\right) \quad 5.1 \mathrm{~Hz}$, and $\left.J_{5,6 \mathrm{a}}\right)$ $10.4 \mathrm{~Hz}$ ) are consistent with a chair conformation for the 1,3-dioxane ring. Ikegami et al. (ref 7a) have demonstrated, in a closely related L-rhamno- Dglucosylidene ortho ester, that the 1,3-dioxane ring adopts a chair conformation in the $R$-isomer, whereas in the $S$-isomer, a skew boat conformation is preferred.

(14) The high propensity of pyranosyl radicals for quenching by stannanes along the axial direction and formation of equatorial glycosides is well established. See, for example: Crich, D.; Sun, S.; Brunckova, J. J. Org. Chem. 1996, 61, 605-615 and references therein. that the abstraction at $\mathrm{C}-1^{\prime}$ occurred with total inversion of configuration.

These results reassured us that the modeling procedure is reliable and that if a 1,3,5-trioxocane ring is formed in a stable boat-chair conformation the abstraction would occur preferentially at C-5'. Contrarily, if this process is energetically disfavored, the abstraction should occur preferentially at $\mathrm{C}-1^{\prime}$. Nevertheless, we are aware that the cyclization step may also be influenced by the nature and stereochemistry of all the substituents of the sugar molecule, not only by the stereochemistry of the trioxocane ring carbons (C-5', C- $1^{\prime}$, $\mathrm{C}-4$, and $\mathrm{C}-5$ ), and that generalizations are difficult at this stage of the research.

Acknowledgment. This work was supported by Research programs CTQ2004-06381/BQU and CTQ2004-02367/BQU of the Ministerio de Educacio'n y Ciencia, Spain, cofinanced by the Fondo Europeo de Desarrollo Regional (FEDER).I.P.M. and L.M.Q. thank the Program I3P-CSIC for fellowships.

Supporting Information Available: A complete description of experimental details and product characterization. This material is available free of charge via the Internet at http://pubs.acs.org.

OL070496Q

(15) The intramolecular migration of esters from 4 to 6 positions of the glucopyranose skeletons is well-documented: (a) Zhang, S.-Q.; Li, Z.-J.; Wang, A.-B.; Cai, M.-S.; Feng, R. Carbohydr. Res. 1997, 299, 281-285. (b) Morales, J. C.; Penade's, S. Tetrahedron Lett. 1996, 37, 5011-5014.

(c) Zhang, Z.; Magnusson, G. J. Org. Chem. 1996, 61, 2383-2393. (d) Machida, K.; Kikuchi, M. Chem. Pharm. Bull. 1993, 41, 248-251. 